\title{
The e-LIVES Project: e-Engineering Where and When Students Need
}

\author{
Manuel Gericota, Paulo Ferreira, Andre Fidalgo \\ School of Engineering - Polytechnic of Porto \\ Porto, Portugal \\ \{mgg, pdf, anf\}@isep.ipp.pt
}

\author{
Guillaume Andrieu, Claire Dalmay \\ University of Limoges \\ Limoges, France \\ \{guillaume.andrieu, claire.dalmay\}@unilim.fr
}

\begin{abstract}
Students' engagement in their learning process is essential for its success. However, many factors out of students' control may impair their learning process leading to demotivation and studies abandonment. Some of these factors are related to low economic conditions. Even in developed countries, higher education is concentrated in medium and large cities, which forces many countryside students into expensive temporary relocations if they want to pursue their studies. The same happens when the existing offer does not match the student's preferences. The problem is even more acute in developing countries where the offer is reduced, and the economic conditions of students are even worse, with many being forced to work from a young age. For these students, the flexibility provided by e-Engineering courses may be the answer to their otherwise bare chances of achieving a higher education degree. In this paper, we present the e-LIVES - e-Learning InnoVative Engineering Solutions project, whose aim is to document a set of good practices, following a hands-on approach, to help Universities to build innovative e-Engineering courses by themselves in a sustainable way.
\end{abstract}

Keywords-e-Engineering, e-learning, remote laboratories

\section{INTRODUCTION}

The growth in the number of students in the tertiary education has been highly encouraged by national governments in developing countries, committed to the development of higher education in advanced engineering fields - physical sciences, computer sciences, engineering, and engineering trades - perceived as essential in making their economies competitive in today's globalized knowledge society.

Figure 1 shows that the steady increase on tertiary education enrollment started in the European countries around the seventies and that on even those, like Portugal, that started only by the middle of the eighties, current enrollment levels are set between the $63 \%$ of Portugal and the $91 \%$ of Spain [1-3]. This steady increase along the last fifty years gave time for countries to adapt their tertiary education infrastructure to the growing number of students looking to pursue higher education studies. By the contrary, the development of higher education in developing countries is much recent but very fast, leaving these countries with an infrastructural problem.

In spite of this increase, many students in developing countries remain outside of the higher education system due to weak economic conditions. Contrary to primary education schools, the creation and maintenance cost of higher education institutions induces a concentration of these establishments in medium and large cities. That is particularly the case in large sparsely populated countries. Consequently, students living far away are forced into expensive temporary relocations they can absolutely not afford.
The same weak economic conditions, especially in the least developed countries, also force many potential students to enter the labor market at an early age. Since school timetables are incompatible with students' long working hours, they are forced to abandon the system.

The expansion of high-quality Internet access even in remote regions enable the implementation of a promising solution able to cope with the lack of infrastructures and of qualified professors while responding to the massive increase in the number of students: the offer of nationally accredited e-learning undergraduate and graduate courses by current Universities.

It was based on this assumption the EOLES project Electronic and Optic e-Learning for Embedded Systems [4] was launched in 2012, a European Tempus project whose motto was "engineering a brighter future anywhere". The purpose of the project was to study, develop, and implement a set of integrated solutions able to support the creation of fully online engineering courses, by bringing together the competencies of the different consortium partners in e-learning and remote virtual and real laboratories. The goal was to have an accredited pilot course as a proof-of-concept to demonstrate the viability of having distance learning also in the engineering field.

The first edition of this engineering course, the L3-EOLES, an "e-Learning 2.0" English-taught 3rd year Bachelor's degree course in Electronics and Optics for Embedded Systems took place in the school year 2014/15 and has been offered every year ever since.

The L3-EOLES course is based on the concept of e-Engineering, which results from the concatenation of two previous ideas: e-learning and remote laboratories [5]. The extensive study published by James Brinson [6], and the experience gained with EOLES [7] demonstrate the effectiveness of the use of virtual and remote laboratories in e-Engineering courses.

Notwithstanding the impulse given by the EOLES project, this was still insufficient to determine a fast expansion on the creation and offer of e-Engineering courses in the short term, a situation the e-LIVES project seeks to overcome.

\section{E-ENGINEERING}

The day-to-day routine of e-Engineering students is similar to that of any other undergraduate engineering students. It is divided among e-Lectures, e-Tutoring, and e-Laboratories, plus their own self-study.

e-Lectures usually consist of pre-recorded instructorproduced videos with an ideal duration not exceeding 6 minutes and where they explain the theoretical basis of a subject supported by different types of visual materials [8]. To 


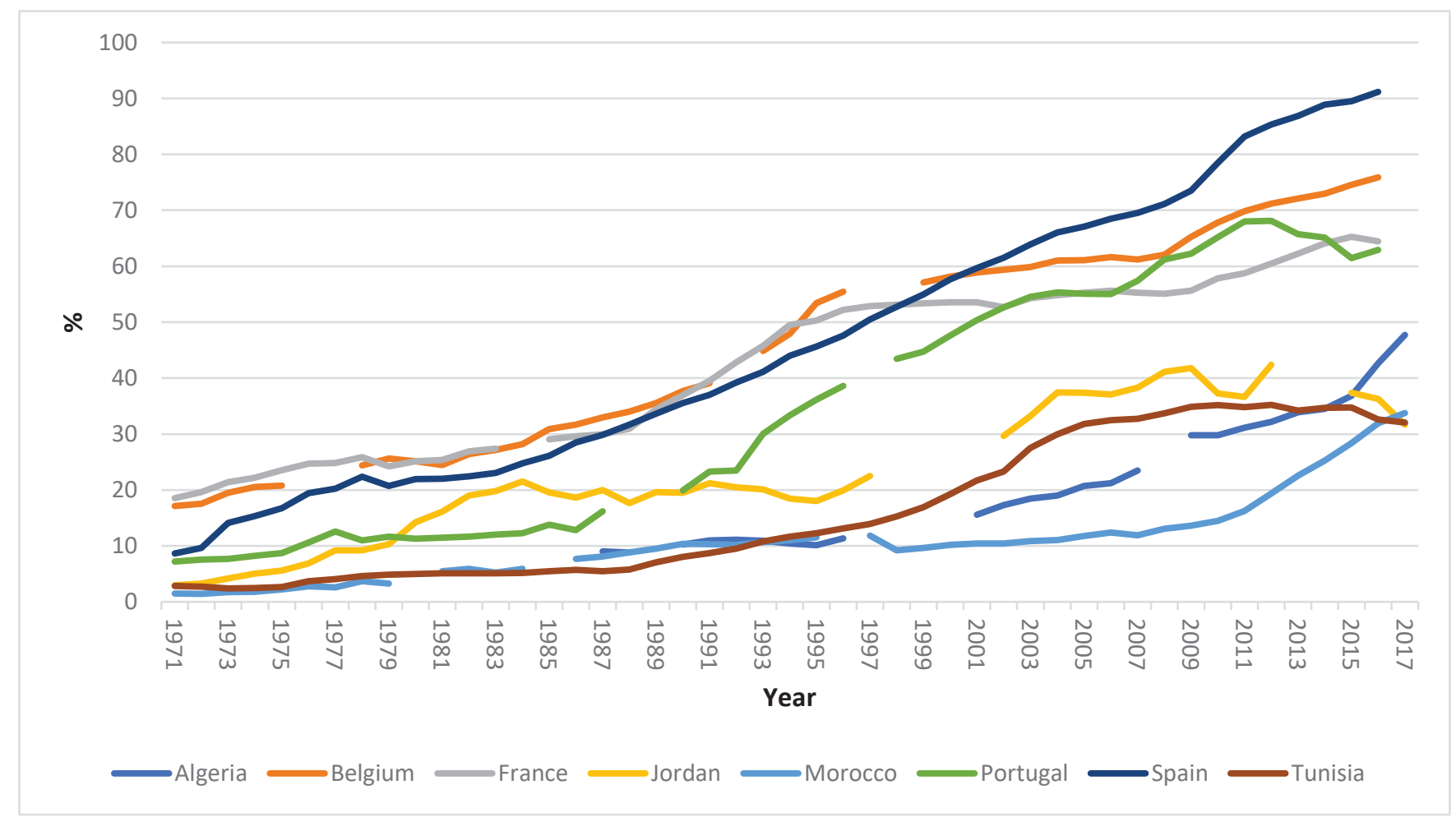

Fig. 1. Gross enrolment ratio for tertiary education in e-LIVES consortium countries

keep students' interest and attention, breaking long expositive lectures, they should be interspersed with self-evaluation questions - multiple-choice, fill-in-the-blanks, matching exercises. Additionally, self-evaluation questions provide students with immediate feedback regarding their degree of understanding of the taught subjects. This methodology is an adaptation of the Just-in-Time Teaching (JiTT) approach [9] to e-Learning, preparing students to the tutorial synchronous sessions.

To allow students to continue their independent self-study anywhere and at any time, even if power and an Internet connection are not immediately available, the lecture materials should be, whenever possible depending on their nature, available to download in a printable format.

A range of other materials including companion books freely downloadable from Internet, web links to other sites containing specialized information and other complementary documentation or applications depending on the subjects, should be available to support the study [10].

e-Tutorial sessions are synchronous sessions based on the use of a web conferencing tool. Their aim is to enable students to clarify any issues and ask questions related to the subjects being study. The duration of these synchronous sessions is not rigid. It depends on the questions and doubts of participating students. Students should be advised to stay connected for the whole duration of the session since they can also learn from colleagues' questions. These sessions should be recorded, and the records made available to students. In this way, students may revise the questions and answers or have access to the session if they were unable to attend it.

Tutorial sessions may also be used to introduce laboratory or project works. A laboratory or project work in an e-Engineering course should follow a generic number of steps [11]:
- During the tutorial session, the instructor describes the work and directs students to all useful documents and to the links to simulation programs, instrumentation devices, and setups accessible through the Learning Management System (LMS) platform;

- During one to two weeks, students have to perform the assigned individual or group work; each setup should be available 24/7 during this period;

- Each student or group of students has to upload his/her/their task report in the LMS platform before the deadline;

- The correction of the work should be made available to students in the LMS platform immediately after the deadline; during the next tutorial session, the instructor may explain the correction of the work and clarify any students' doubts about it;

- After this session, the instructor corrects, annotates and evaluates the report submitted by each student, making the results available in the LMS platform.

For students to be able to target their learning problems and to improve their knowledge, to provide timely feedback about their assignments is crucial.

During the synchronous sessions, instructor and students should have their cameras on to have visual feedback of the entire class, making them feel part of a community and encouraging the interaction not only with the instructor but also among each other [12].

Successful undergraduate degrees in engineering areas demand students to perform experimental work to acquire technical skills in subjects like physics, chemistry, mechanical and electrical machines, or digital and analog electronics, for example. Engineering professions are imminently devoted to the creation of technology through the manipulation of 
energy, materials, and information. Engineering education must prepare students to practice engineering. Thus, instructional laboratories are an essential part of the undergraduate students training [13]. This conclusion is shared by engineering students who see themselves as essentially practical, and thus recognize laboratory work as an important component of their formation [14]. It is, therefore, essential for students to have access to virtual or remote laboratories - e-Laboratories - during their e-Engineering courses.

In virtual laboratories, computational simulations based on accurate mathematical models replace the physical laboratory. In this case, the virtual laboratory is used to achieve the same learning outcomes as the corresponding real laboratory. Students have the opportunity to perform experimental work in a context similar to that of a practicing engineer in the industry, but with a wider design space than in a typical undergraduate laboratory and without access time restrictions [15].

A second approach is to allow students to remotely access experimental laboratories, providing real-time interaction with real experimental setups. However, many of the first remote labs did not provide the user with a feeling of real presence in the lab [16].

For students to remotely acquire similar practical skills when compared to the ones they may attain in an on-site laboratory, they need to feel that they are using real devices and controlling real instrumentation. For this reason, they need to remotely be able to control instrumentation and to change hardware configuration in real-time, having immediate feedback of their actions, which requires each hardware setup to be connected to the Internet. Students must be able to control each instrument via the virtual instrument's interface that is remotely deployed and receive instant feedback of their actions through the same virtual instrument interface and through a high-definition camera or another interface, depending on the experiment [10]. This feedback is important for students to feel the interface they see in their own computer monitors is not the visible face of a virtual environment but the virtual interface of a real instrument [12].

Asynchronous forums and synchronous live chat resources should be freely accessible to students through the LMS platform during the entire course. These resources give students a chance to interact with colleagues and to be proactive in their own learning progression while enabling them to feel part of a community. It also helps to counter the loss of motivation in the face of di: ficulties, both personal or due to demanding subjects, creatng a supportive network and preventing drop out. 'urthermore, by encouraging collaboration, it is expected an improvement in students' theoretical and practical skills and in their English language level. Bonus points may he attributed at the instructor's discretion to each student to rize his/her level of participation in the synchronous sessions, forums, and live chats [7].

\section{E-LIVES}

Apart from the relevant pedagogical aspects mentioned in the previous section, strictly correlated with the deliver of the course, the development, and management of an e-Engineering course involve a series of other essential elements, namely: the set up of the necessary infrastructure to support course delivery; the choice of the LMS platform; the building of a curriculum; the definition of the learning modules content and schedule; the attainment of the course national accreditation; the training of teachers and technicians; the creation of the contents; the quality assessment; the management of the course; the development of the virtual and remote laboratories.

The lessons learned with the L3-EOLES course and its success drew the attention of Universities in other countries also interested in the development of e-Engineering courses. Notwithstanding the success story of this previous EOLES project, its purpose was restricted to the creation of one e-Engineering course. The idea was to integrate the different background knowledge of the different partners to build and run an e-Engineering course, experiment and correct any flaws. No dissemination mechanisms able to support the creation of other e-Engineering courses were planned. This is the main shortcoming of the EOLES project that the new e-LIVES - e-Learning InnoVative Engineering Solutions project [17], a three-year ERASMUS+ European project that started on October 2017, seeks to overcome.

The aim of the e-LIVES consortium is to create a detailed description of the different parts need to set up and run a successful e-Engineering course supported on the consortium partners own successful experience. The produced documentation will list and detail each one of the steps necessary to design and develop an e-Engineering course.

The consortium will also produce and make available on the project website, for download and discussion with all actors interested in this thematic, a pedagogical Best Practices guide that condenses the partners' research and experience on the creation and delivery of e-Learning and e-Engineering courses.

Essential to e-Engineering courses, the development and implementation of a remote laboratory to support the experimental part of the e-Engineering course is a critical component for its success by enabling students to acquire essential skills for the exercise of the engineering profession. The consortium will design a reference remote practical work supported by a remote laboratory infrastructure. It will be used as an example in the production of a detailed guideline any University may follow to create their own remote laboratory, adapted to the specific needs of their own e-Engineering courses.

Apart from the laboratory in itself, there is a panoply of other aspects that are necessary to take care to put the laboratory online.

From the student's point of view, it is necessary to have an access control mechanism, and a scheduling scheme or a configuration and access first-in-first-out buffer, depending on the experiment.

From the University's point of view, it is necessary to guarantee the security of the accesses, preventing security attacks by hackers.

Depending on the e-Engineering program, several remote laboratories for different subjects will be used. Therefore, each University will have to have a Remote Laboratory Management Systems to support students' access control, while providing security, scalability, and reliability to the remote laboratories. 
Through this system, every remote practical work will be easily integrated into the LMS platform. Guidelines on how to choose, develop and install these Remote Laboratory Management Systems will be produced by the consortium.

At the end of the e-LIVES project, Universities will have available a set of documents describing how to create, implement and run an e-Engineering course, through the description of a set of good practices and following a hands-on approach. The ultimate goal is to help Universities to build innovative e-Engineering courses by themselves in a sustainable way.

The long-term purpose of the e-LIVES project is to generate a more active and professional environment ready to introduce new forms of flexible learning and to create and manage accredited e-Engineering courses.

\section{E-ENGINEERING ALLIANCE}

The e-Engineering Alliance Special Interest Group was created within the International Association of Online Engineering, a non-profit organization whose aim is to promote the broader development, distribution, and application of Online Engineering technologies, to guarantee the sustainability and exploitation of the knowledge generated during the e-LIVES project and its everlasting use after the project's end [18].

The e-Engineering Alliance aims to be a forum where all Universities giving or seeking to offer e-Engineering courses may share their experiences and develop new forms of cooperation. By breaking the physical barriers of the classroom, e-Engineering opens new possibilities of cooperation among Universities. New shared courses may be offered to students that, without needing to relocate several times during it, as it happens with current Erasmus Mundus courses, for example, may have access to the best each University has to offer in different subject areas.

\section{CONCLUSIONS}

e-Engineering still is in its outset, with a lot of questions yet to be answered and problems to be solved. The e-LIVES project aims to contribute to the advancement and consolidation of the e-Engineering concept by, based on the experience gained by their consortium members, documenting all the steps necessary for Universities to successfully create their own e-Engineering courses.

\section{ACKNOWLEDGMENT}

The EOLES and e-LIVES projects are funded by the European Commission under contract numbers 530466TEMPUS-1-2012-1-FR-TEMPUS-JPCR and 585938-EPP-12017-1-FR-EPPKA2-CBHE-JP respectively.

The European Commission support for the production of this publication does not constitute an endorsement of the contents which reflects the views only of the authors, and the Commission cannot be held responsible for any use which may be made of the information contained therein.

\section{REFERENCES}

[1] "Six ways to ensure higher education leaves no one behind", Policy Paper 30, Global Education Monitoring Report, United Nations Educational, Scientific and Cultural Organization (UNESCO), 2017
[2] "Accountability in education: Meeting our commitments", Global Education Monitoring Report Summary 2017/8, $2^{\text {nd }}$ edition, United Nations Educational, Scientific and Cultural Organization (UNESCO), 2017

[3] Data collected from the UNESCO Institute for statistics (2018), in Gross enrolment ratio by level of education. Accessed 11 December 2018. Retrieved from http://uis.unesco.org/

[4] Electronic and Optic e-Learning for Embedded Systems - engineering a brighter future anywhere, EOLES, Accessed 14 October 2018. Retrieved from http://www.eoles.eu/

[5] Manuel Gericota, Guillaume Andrieu, Claire Dalmay, Majd Batarseh, Andre Fidalgo, Paulo Ferreira, "E-Engineering: from concept to reality", Proc. 10th Intl. Conf. on Education and New Learning Technologies, Palma de Mallorca, Spain, July 2018, pp. 1256-1261.

[6] J. R. Brinson, "Learning outcome achievement in non-traditional (virtual and remote) versus traditional (hands-on) laboratories: A review of the empirical research", Computers \& Education, vol. 87, pp. 218-237, 2015.

[7] Guillaume Andrieu, Denis Barataud, Manuel Gericota, "L3-EOLES Electronics and Optics for Embedded Systems course," In: The e-Learning Excellence Awards 2017: An Anthology of Case Histories (Dan Remenyi, ed.), pp. 22-35, Academic Conferences and Publishing International Limited, 2017.

[8] Philip J. Guo, Juho Kim, Rob Rubin, "How video production affects student engagement: An empirical study of MOOC videos", Proc. of the first ACM conference on Learning@ scale conference, Atlanta, Georgia, USA, March 2014, pp. 41-50.

[9] G. M. Novak, E. Patterson, A. Gavrin, W. Christian. 1999. Just-inTime Teaching: Blending active learning with Web technology. Upper Saddle River: Prentice Hall.

[10] Manuel Gericota, Andre Fidalgo, Denis Barataud, Guillaume Andrieu, Renaat De Craemer, Mihail Cristea, Abdelhalim Benachenhou, Mohammed Ankrim, Karim Bouchlaghem, Paulo Ferreira, "EOLES course - The first accredited on-line degree course in Electronics and Optics for Embedded Systems", Proc. of the IEEE Global Engineering Education Conference (EDUCON'2015), Tallinn, Estonia, March 2015, pp. 410-417.

[11] Guillaume Andrieu, Said Farah, Thomas Fredon, Abdelhalim Benachenhou, Mohammed Ankrim, Karim Bouchlaghem, Noura Aknin, Denis Barataud, Manuel Gericota, Renaat De Craemer, Mihail Cristea, "Overview of the first year of the L3-EOLES training", Proc. of the 13th International Conference on Remote Engineering and Virtual Instrumentation (REV'2016), Madrid, Spain, February 2016, pp. 396-399.

[12] Manuel Gericota, Andre Fidalgo, Denis Barataud, Guillaume Andrieu, Renaat De Craemer, Mihail Cristea, Abdelhalim Benachenhou, Mohammed Ankrim, Karim Bouchlaghem, Paulo Ferreira, "Combining E-Technologies \& E-Pedagogies to Create Online Undergraduate Courses in Engineering - an Example of a Successful Experience", Proc. of the 8th Intl. Conf. on Education and New Learning Technologies (EduLearn'2016), Barcelona, Spain, July 2016, pp. 4209-4218.

[13] Lyle D. Feisel, Albert J. Rosa, "The Role of the Laboratory in Undergraduate Engineering Education" Journal of Engineering Education, Vol. 94, Issue 1, pp. 121-130, January 2005.

[14] Norrie S. Edward, "The Role of Laboratory Work in Engineering Education: Student and Staff Perceptions." Intl. Journal of Electrical Engineering Education, Vol. 39, no. 1, pp. 11-19, January 2002.

[15] Milo D. Koretsky, Danielle Amatore, Connelly Barnes, Sho Kimura, "Enhancement of Student Learning in Experimental Design Using a Virtual Laboratory," in IEEE Transactions on Education, vol. 51, no. 1, pp. 76-85, Feb. 2008.

[16] George D. Peterson, Lyle D. Feisel, "e-Learning: The challenge for engineering education." Proc. of the e-Technologies in Engineering Education Conference, Davos, Switzerland, pp. 164-169, August 2002.

[17] e-LIVES - Extending e-Engineering along the South and Eastern Mediterranean Basin. Accessed 8 December 2018. Retrieved from https://e-lives.eu/

[18] e-Engineering Alliance. Accessed 18 December 2018. Retrieved from https://e-lives.eu/?page_id=4572 